\title{
Analisis Menggambar Doodle Terhadap Kreativitas Anak Usia Dini
}

\author{
Silvia Novi Yanti ${ }^{\circledR}$, Farida Mayar² \\ Pendidikan Anak Usia Dini, Universitas Negeri Padang, Indonesia(1) \\ DOI: 10.31004/obsesi.v6i3.2018
}

\begin{abstract}
Abstrak
Doodle adalah gambar sederhana yang dapat memiliki makna representasi konkret atau yang terdiri dari garis acak dan abstrak, dalam hal ini biasanya disebut "coretan". Teknik Menggambar Doodle dilakukan dengan tujuan untuk mengasah kemampuan seni anak sehingga mampu meransang perkembangan dan kreativitas anak. Metode yang digunakan dalam penelitian ini adalah metode deskriptif kualitatif dengan teknik pengumpulan data melalui wawancara dan dokumentasi. Hasil dari penelitian ini dapat dilihat dari kemampuan menggambar anak, selain itu juga terlihat dari semangat, minat, dan anak idik dalam melakukan kegiatan menggambar. Kreativitas anak juga terlihat dari adanya ide-ide baru dalam menggambar yang di lakukan anak. Sehingga dapat dikatakan bahwa menggambar doodle dapat meningkatkan kreatifitas kemampuan menggambar anak.
\end{abstract}

Kata Kunci: Menggambar; Doodle; Kreativitas

\begin{abstract}
A doodle is a simple drawing that can have a concrete representational meaning or that consists of random and abstract lines, in which case it is usually called a "doodle". The Doodle Drawing technique is carried out with the aim of honing children's artistic abilities so that they are able to stimulate children's development and creativity. The method used in this research is descriptive qualitative method with data collection techniques through interviews and documentation. The results of this study can be seen from the ability to draw children, besides that it can also be seen from the enthusiasm, interest, and children in doing drawing activities. Children's creativity can also be seen from the new ideas in drawing that children do. So that it can be said that drawing doodles can increase the creativity of children's drawing abilities
\end{abstract}

Keywords: Drawing; Doodles; Creativity

Copyright (c) 2021 Silvia Novi yanti, Farida Mayar.

$\triangle$ Corresponding author :

Email Address : snovianti0404@gmail.com (Pasaman, Sumatera Barat, Indonesia)

Received 26 August 2021, Accepted 21 December 2021, Published 29 December 2021

\section{PENDAHULUAN}

Anak usia dini merupakan aset bangsa yang harus mendapat perhatian dari berbagai pihak yang bertanggung jawab. Anak usia dini adalah anak yang baru dilahirkan sampai usia enam tahun (Suryana, 2016). Usia ini sangat menentukan karakter dan kepribadian anak. Anak usia dini memiliki karakteristik yag berbeda dengan orang dewasa, karena anak usia dini tumbuh dan berkembang dengan banyak cara dan berbeda (Lillard et al., 2013). Anak usia 
dini memiliki karakteristik unik karena mereka berada pada proses tumbuh kembang sangat pesat dan fundamental bagi kehidupan berikutnya (Arakawa et al., 2020).

Beberapa macam karakteristik yang dimilik anak yaitu 1) bersifat egosentris naif, 2) mempunyai relasi sosial dengan benda-benda dan manusia yang sifatnya sederhana dan primitif, 3) ada kesatuan jasmani dan rohani yang hampir-hampir tidak terpisahkan sebagai satu totalitas, 4) sikap hidup yang fisiognomis, yaitu anak secara langsung membertikan atribut/sifat lahiriah atau materiel terhadap setiap penghayatanya (Fatimah \& Rohmah, 2016). Karakteristik anak usia dini hendaknya dapat dipahami oleh orangtua dan guru serta masyarakat lainnya. Dengan mengetahui karakteristik anak maka akan mudah dalam memberikan penaganan perilaku dan pendidikan yang tepat kepada anak, sehingga anak akan tumbuh dengan optimal sesuai yang diinginkan (Carina Girvan, Claire Conneely, 2016).

Berbagai upaya dilakukan untuk memenuhi kebutuhan berkembang anak agar mampu mengoptimalkan segala potensi yang ada pada dirinya, salah satunya adalah dengan Pendidikan anak usia dini. Pendidikan anak usia dini pada hakikatnya ialah Pendidikan yang diselenggarakan dengan tujuan untuk memfasilitasi pertumbuhan dan perkembangan anak secara menyeluruh atau menekankan pada perkembangan seluruh aspek kperibadian anak (Darihastining et al., 2019). Oleh karena itu, PAUD memberikan kesempatan kepada anak untuk mengembangkan kepribadian dan potensi secara maksimal. Konsekuensinya, Lembaga PAUD perlu menyediakan berbagai kegiatan yang dapat mengembangkan berbagai aspek perkembangan seperti: kognitif, bahasa, sosisal, emosi, fisik dan motorik (Bereczki \& Kárpáti, 2021).

Tujuan utama pendidikan anak usia dini adalah untuk membentuk anak Indonesia yang berkualitas, yaitu anak yang tumbuh dan berkembang sesuai dengan tingkat perkembangannya sehingga memiliki kesiapan yang optimal di dalam memasuki pendidikan dasar serta memiliki perkembangan kreatifitas yang baik (Pizzingrilli et al., 2015). Secara umum tujuan pendidikan anak usia dini ialah memberikan stimulasi atau ransangan bagi perkembangan potensi anak agar menjadi manusia beriman dan bertaqwa kepada tuhan yang maha esa, berakhlak mulia, sehat, berilmu, cakap, kritis, kreatif, inovatif, mandiri, percaya diri serta menjadi warga negara yang demokratis dan bertanggung jawab (Chatterjee, D. S., Biswas, S. J., \& Adhikary, 2014).

Potensi yang diharapkan tersebut salah satunya adalah kreatifitas. Kreativitas secara umum dipengaruhi oleh adanya berbagai kemampuan yang dimiliki, sikap dan minat yang positif, serta kecakapan melaksanakan kegiatan. Kreativitas memang tidak dapat dipaksakan, tetapi harus dimungkinkan untuk tumbuh (Fitriyah et al., 2022). Kreatifitas yang sering kita dengar dan kita ucapkan kepada anak- anak sayangnya masih banyak guru tidak mengetahui makna kata kretif. Sebagian guru mengatakan kata kreatif dengan wujud karya seni, tetapi Guru tidak melihat dengan baik bahwa masih banyak anak- anak yang kurang kreatif karena yang diajarkan guru di sekolah hanya itu- itu saja. Jadi dengan melihat itu saja perkembangan kreativitas anak tentunya harus latih dan ditingkatkan keterampilannya ((Sari \& Nofriyanti, 2019). Keterampilan yang dapat digunakan dalam pengembangan kreativitas anak salah satunya adalah doodling (Podobnik et al., 2021).

Doodling adalah teknik menggambar dengan cara mencoret-coret (Pizzingrilli et al., 2015). Teknik doodling dilakukan pada sebidang kertas dengan berbagai media seperti pensil, pensil warna maupun spidol (Kaimal et al., 2017). Aktifitas yang dilakukan anak dengan mencoret-coret adalah kreativitas spontan, dapat dilakukan sendiri oleh anak tanpa bantuan orang dewasa, namun bila di bimbing dengan baik dan benar maka akan mendapatkan suatu hasil yang maksimal (Debeturu \& Wijayaningsih, 2019). Agar anak mendapatkan hasil karya doodle dengan baik, maka guru perlu mengetahui langkah-langkah dari proses membuat karya tersebut, dan anak juga dapat memahami proses pelaksanaannya.

Teknik doodling ini dilakukan dengan memperhatikan tingkat perkembangan kemampuan menggambar anak secara bertahap. Anak dilatih dengan teknik doodling agar gambar yang dibuat menyerupai objek aslinya, sehingga anak mampu menguasai indikator 
menggambar sesuai gagasan pada tahap perkembangan yang seharusnya (Kaimal et al., 2017). Selain itu, dalam doodling art anak dapat dilatih menggambar dengan cara yang sederhana, kemudian selanjutnya anak diarahkan untuk membentuk atau menambahkan coretan yang lain hingga membentuk suatu gambar yang menyerupai objek aslinya (Platokhina et al., 2016). Dalam prakteknya yang peneliti temukan dilapangan, dalam pembelajaran seni guru cenderung memakai metode imitasi, dimana guru akan memberikan sebuah gambar dan meminta anak untuk mewarnai gambar tersebut. Pada aktivitas menggambar, guru akan mencontohkan di papan tulis kemudian meminta anak menyalin apa yang dilihat ke buku gambar mereka. Seolah pembelajaran seni yang diberikan terlalu monoton. Pada penelitian yang dilakukan oleh (Podobnik et al., 2021) terdapat Dampak doodling art terhadap kemampuan menggambar anak. Teknik doodling yang diberikan dilakukan dengan memperhatikan tingkat perkembangan kemampuan menggambar anak secara bertahap.

Oleh karena itu, dengan menggambar doodle diharapkan dapat berpengaruh terhadap perkembangan kreativitas anak, sehingga anak lebih bersemangat dalam melakukan kegiatan menggambar. Anak-anak juga dapat menemukan ide-ide baru dalam menggambar yang di lakukan. Secara garis besar penelitian ini nantinya dapat meningkatkan kreatifitas kemampuan menggambar anak di Raudhatul Athfal Ath Thaharah KODIM 0305 Pasaman.

\section{METODOLOGI}

Penelitian menggunakan metode deskriptif kualitatif. Penelitian dilakukan pada lembaga Raudhatul Athfal Ath Thaharah KODIM 0305 Pasaman dengan melihat teknik menggunaka doodle dalam peningkatan kreativitas anak. Teknik pengumpulan data melalui wawancara dan dokumentasi. Alat observasi yang digunakan berbentuk format wawancara dilakukan pada narasumber di lembaga-lembaga yang berkaitan dengan perlindungan anak. Data dokumentasi berupa foto, rekaman dan video sebagai lampiran untuk memperkuatkan hasil penelitian. Proses penelitian dapat dilihat pada gambar 1.

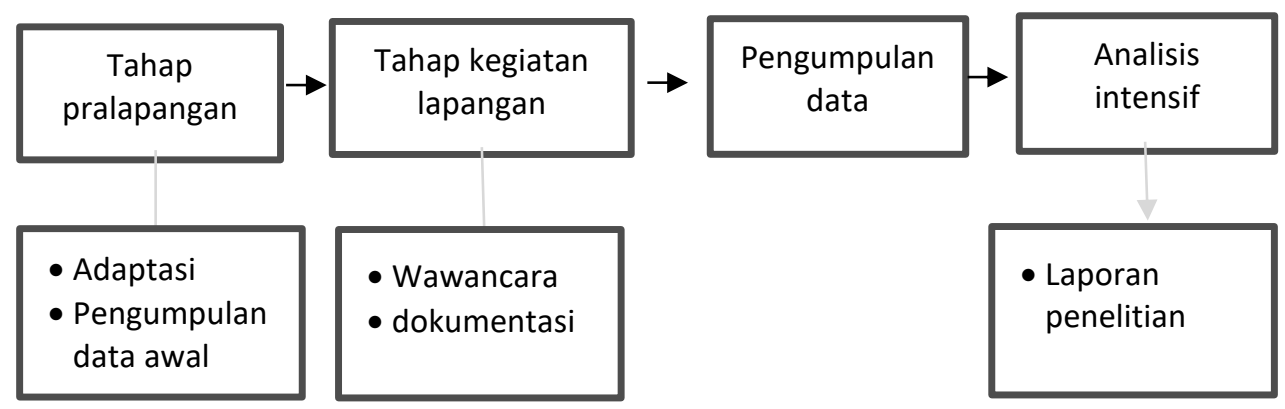

\section{Gambar 1. Proses penelitian}

\section{HASIL DAN PEMBAHASAN}

\section{Perencanaan Pelaksanaan menggambar doodle}

Perencanaan perlu dilakukan sebelum proses pembelajaran dilaksanakan. Begitupun penelitian yang sudah dilakukan di Raudhatul Athfal Ath Thaharah KODIM 0305 Pasaman. Sebelum dilaksanakan penelitian terlebih dahulu melihat dokumen-dokumen terkait, seperti RPPH ataupun foto pelaksanaan pembelajaran disekolah tersebut. Dari situ dapat diketahui bahwa sekolah yang bersangkutan sudah melaksanakan teknik menggambar doodle.

Tahap perencanaan ini juga melihat bahwa ada beberapa langkah untuk memulai menggambar doodle ini. Adapun langkah-langkah pelaksanaannya adalah: 1) guru terlebih dahulu memberikan penjelasan tentang kegiatan apa yang akan dilakukan, 2) guru menjelaskan alat dan bahan yang akan digunakan serta aturan bermain, 3) guru memberikan informasi atau penjelasan tentang hal-hal yang akan digambar anak, 4) guru memberikan 
contoh kepada anak cara membuat doodle, 5) guru memberikan kesempatan kepada anak untuk membuat gambar dengan pensil ataupun pensil warna.

Jadi dalam penelitian ini penulis bersama guru menggunakan beberapa langkah untuk melaksanakan proses pembelajaran menggambar doodle. Teknik doodle yang diajarkan pada anak tidak terlepas dari bimbingan guru. Artinya proses pembelajaran doodle ini dengan bimbingan guru dapat memberikan kesempatan kepada anak memodifikasi atau mengrekreasi karya anak dengan baik dan benar (Saliceti, 2015)

\section{Pelaksanaan kegiatan menggambar doodle}

Pelaksanaan pembelajaran dilaksanakan sesuai RPPH yang sudah dirancang dan sesuai dengan langkah-langkah pembelajaran yang sudah direncanakan. Kegiatan pembelajaran di Raudhatul Athfal Ath Thaharah KODIM 0305 Pasaman dimulai dari kegiatan pembuka, yaitu anak-anak berbaris di depan kelas masing-masing untuk melakukan gerakan sederhana melalui nyanyian, kemudian masuk ke kelas dengan bersalaman dengan guru kelas. Kemudian anak duduk meja dan kursi dengan melingkar kadang juga membanjar.

Setelah pembukaan pembelajaran sudah dilaksanakan, maka guru memulai pembelajaran inti dengan media yang sudah dipersiapkan. Karena proses pembelajaran dengan menggunakan media sangat membantu guru dalam proses pembelajaran yang efektif dan efisien (Nasution et al., 2019). karena penelitian ini kita terfokus untuk melihat kreatifitas anak, anak dipersilahkan untuk mengambil pensil, pensil warna dan kertas yang sudah disiapkan guru untuk menggambar. Proses menggambar dengan teknik doodle digambarkan pada gambar 2 .
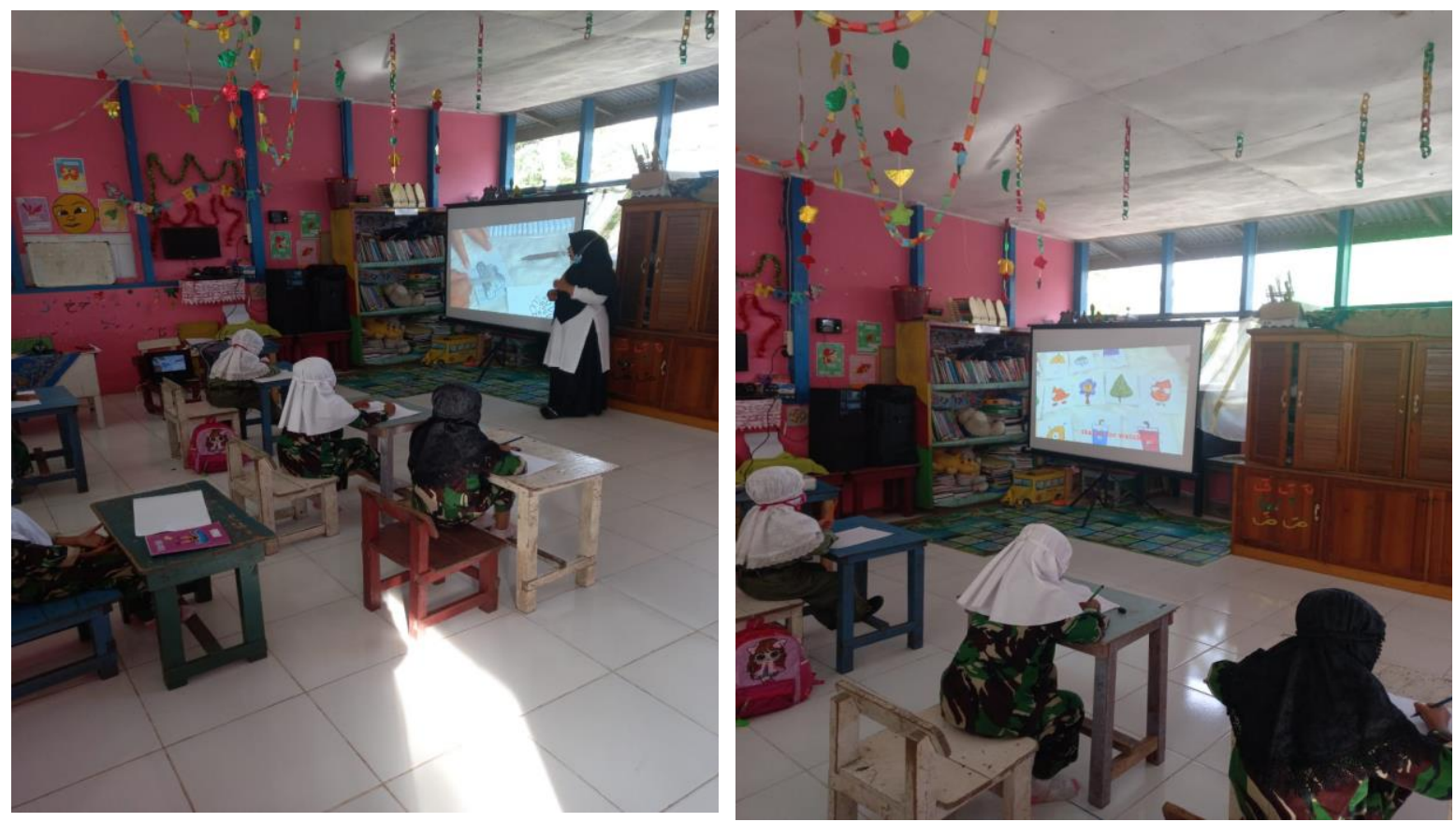

\section{Gambar 2. Proses menggambar dengan teknik doodle}

Kreativatas dipandang sebagai suatu proses untuk menghasilkan sesuatu yang baru, atau kemampuan seseorang untuk menghasilkan sesuatu yang baru yang memiliki sebuah keunikannya tersendiri (Park \& Choi, 2021). Atau ada juga yang mengatakan bahwa kreativitas itu lahir dari perpaduan antara kemampuan, keterampilan, motivasi dan sikap seseorang (Shalihat et al., 2021). Hal ini sejalan dengan pendapat (Wahyuningsih et al., 2019) yang mengartikan kreativitas sebagai kemampuan yang dimiliki seseorang untuk menciptakan sesuatu yang baru, baik berupa produk, ide, gagasan, yang baru untuk 
memecahkan masalah dan sebagai kemampuan untuk melihat unsur-unsur yang ada sebelumnya.

Setelah bahan dan alat untuk doodle, anak dipersilahkan untuk membuat gambar yang sudah disiapkan guru, anak mencontoh gambar tersebut, dan anak juga dipersilahkan untuk membuat kreasi dari gambar yang sudah ada, misalnya dengan menambah pewarna yang menarik, atau menambah bagian yang bias dibuat coretan dan garis-garis. Dalam hal ini anakanak memang dipersilahakan mengekspresikan pengetahuan ataupun ide-ide baru yang dapat membentuk karya dari sang anak. Tahap akhirnya anak diberi penilaian dari guru baik berupa hadiah ataupun penilaian seperti bintang dan angka.

Dari penelitian ini dapat dilihat bahwa tujuan mengembangkan kreativitas anak yaitu :1) Mengenal cara mengekspresikan diri melalui hasil karya dengan menggunakan teknikteknik yang dikuasainya. 2) Mengenalkan cara dalam menemukan alternatif pemecahan masalah. 3) Membuat anak memiliki sikap keterbukaan terhadap perasaannya. 4) Pengalaman dengan tingkat kelenturan dan toleransi yang sangat tinggi terhadap ketidakpastian. 5)Membuat anak memiliki kepuasan diri terhadap apa yang dilakukannya dan sikap menghargai hasil karya orang lain.

\section{Penilaian}

Penilaian terhadap anak didik dilakukan secara terencana, sistematis, dan berkesinambungan. Di samping itu penilaian dapat memberiakan umpan balik bagi guru agar mampu menyempurnakan proses pembelajaran (Mardliyah et al., 2020). Penilaian yang diperoleh peneliti dari hasil wawancara dan dokumentasi di lembaga Raudhatul Athfal Ath Thaharah KODIM 0305 Pasaman menunjukkan bahwa menggambar doodle yang dilaksanakan membuat anak lebih semangat dan antusias. Selain itu anak menjadi lebih kreatif. Hal ini dapat dilihat ketika anak dapat mengkreasikan gambar dengan sesuatu yang belum ada digambar tersebut. Gambaran Hasil menggambar teknik doodle dapat dilihat pada gambar 3 dan 4 .
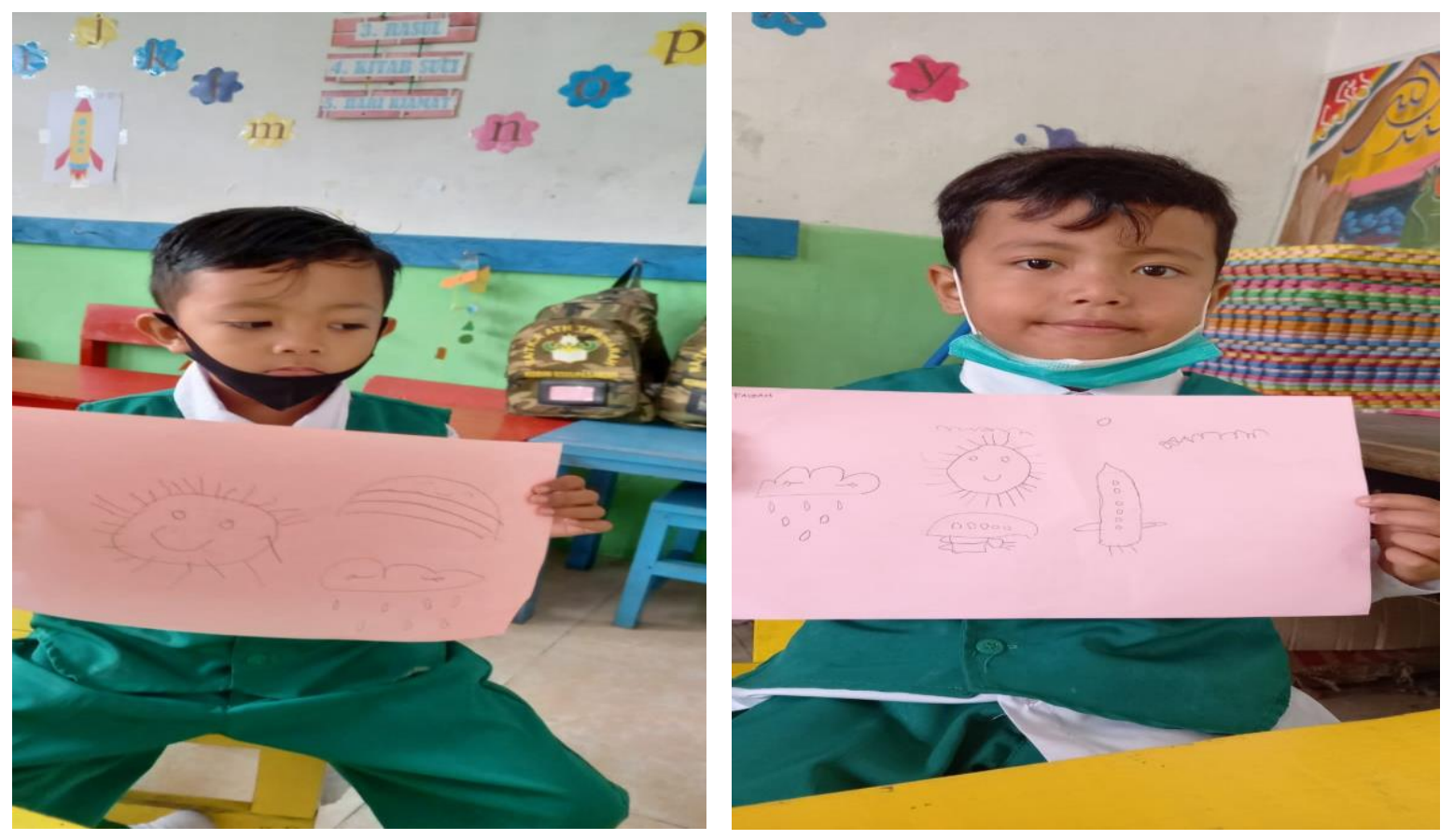

Gambar 3. Hasil menggambar teknik doodle 

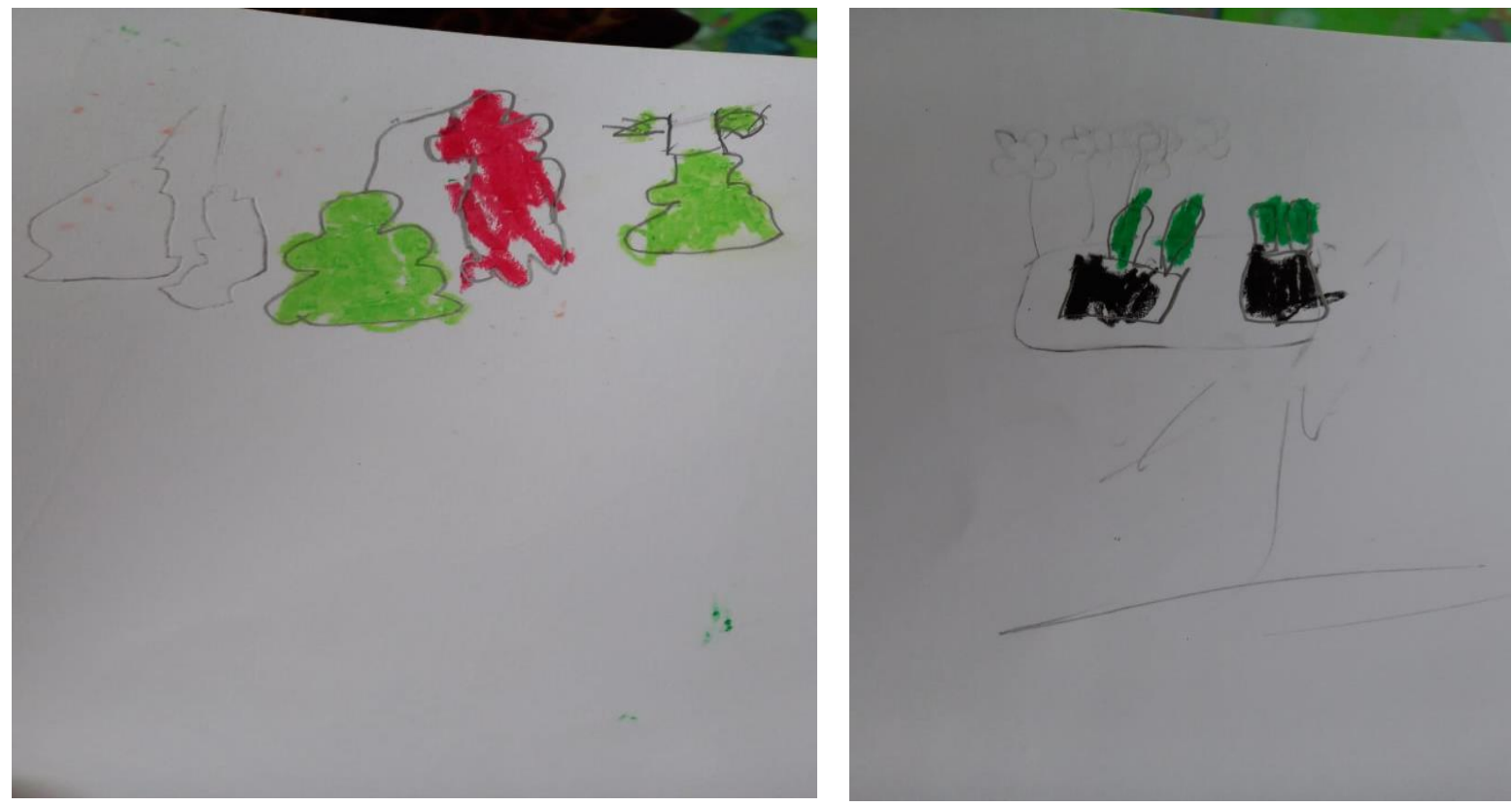

\section{Gambar 4. Hasil gambar yang diwarnai}

Untuk itu diketahui hasil bahwa menggambar doodle ini dapat menumbuhkan kreatifitas anak, karena menggambar doodle anak tidak monoton dengan satu gambar saja. Senada dengan pendapat (Marwiyati \& Istiningsih, 2021) bahwa menggambar doodle sesuai dengan aspek-aspek dari kreativitas. Aspek-aspek kreativitas adalah sebagai berikut: 1) Fluency, yaitu kesigapan, keancaran untuk menghasilkan banyak gagasan; 2) Fleksibilitas, yaitu kemampuan untuk menggunakan bermacam-macam pendekatan dalam mengatasi persoalan; 3) Orisinalitas, yaitu kemampuan untuk mencetuskan gagsan yang asli; 4) Elaborasi, yaitu kemampuan untuk melakukan hal-hal secara detail atau terperinci; 5) Redefinition, yaitu kemampan untuk merumuskan batasan-batasan dengan melihat dari sudut yang lain daripada cara-cara yang lazim. Ciri ciri kreatifitas dapat dikelompokkan dalam dua kategori yaitu kognitif dan nonkognitif. Ciri kognitif diantaranya orisinalitas, fleksibilitas, kelancaran dan elaborasi. Sedangkan ciri nonkognitif diantaranya motivasi, sikap dan kepribadian kreatif.

\section{SIMPULAN}

Analisis menggambar doodle ini di Raudhatul Athfal Ath Thaharah KODIM 0305 Pasaman dengan teknik penelitian wawancara, observasi dan dokumentasi berjalan dengan baik. Penelitian ini juga membuktikan bahwa anak dapat mengembangkan kreativitanya. kreativitas anak dapat dilihat dari kemampuan menggambar anak, selain itu juga terlihat dari semangat, minat, dan anak didik dalam melakukan kegiatan menggambar. Kreativitas anak juga terlihat dari adanya ide-ide baru dalam menggambar yang di lakukan anak. Dengan demikian tujuan pembelajaran yang diharapkan tercapai dengan baik disekolah tersebut, sehingga dapat diterapkan teknik menggambar doodle untuk meningkatkan kreativitas anak ini disetiap sekolah PAUD lainnya.

\section{UCAPAN TERIMA KASIH}

Penulis ucapkan terima kasih kepada koordinator dan dosen Program Studi PAUD fakultas ilmu pendidikan Universitas Negeri Padang yang memberikan masukan dan motivasi dalam penulisan artikel ini serta keluarga dan teman-teman yang telah memberikan dukungan kepada penulis dalam menulis artikel ini. 


\section{DAFTAR PUSTAKA}

Arakawa, H., Adachi, Y., Ebisawa, M., Fujisawa, T., Ebisaw, M., Akasawa, A., Inoue, T., Ohya, Y., Kameda, M., Kurihara, K., Shimojo, N., Suehiro, Y., Mochizuki, H., Yoshihara, S., Iwanaga, T., Kuroki, H., Takase, M., Masuko, I., Hirai, K., ... Nishima, S. (2020). Japanese guidelines for childhood asthma 2020. Allergology International, 69(3), 314330. https:// doi.org/10.1016/j.alit.2020.02.005

Bereczki, E. O., \& Kárpáti, A. (2021). Technology-enhanced creativity: A multiple case study of digital technology-integration expert teachers' beliefs and practices. Thinking Skills and Creativity, 39(January). https:// doi.org/10.1016/j.tsc.2021.100791

Carina Girvan, Claire Conneely, B. T. (2016). Extending Experiental Learning in Teacher Professional Development. Teaching and Teacher Education, 129-139. https:// doi.org/10.1016/j.tate.2016.04.009

Chatterjee, D. S., Biswas, S. J., \& Adhikary, D. S. R. (2014). A Study on the Relationship between Nutrition Status and Physical Fitness of School Boys. IOSR Journal of Sports and Physical Education, 1(5), 46-50. https:// doi.org/10.9790/6737-0154650

Darihastining, S., Ambarwati, A., Kustiyarini, K., \& Sulistyaningsih, E. (2019). Jombang Local Stage Literary As The Strengthening Media For Character Education of Cultural Literacy. SSRN Electronic Journal. https:// doi.org/10.2139/ssrn.3493601

Debeturu, B., \& Wijayaningsih, E. L. (2019). Meningkatkan Kreativitas Anak Usia 5-6 Tahun melalui Media Magic Puffer Ball. Jurnal Obsesi : Jurnal Pendidikan Anak Usia Dini, 3(1), 233. https:// doi.org/10.31004/obsesi.v3i1.180

Fatimah, D. F., \& Rohmah, N. (2016). Pola Pengelolaan Pendidikan Anak Usia Dini di PAUD Ceria Gondangsari Suowono Jawa Tengah: Tahun Pelajaran 2015-2016. Manageria: $\begin{array}{llll}\text { Jurnal Manajemen } & \text { Pendidikan ISlam, 27(2), }\end{array}$ https:// doi.org/10.14421/manageria.2016.12-05

Fitriyah, Q. F., Purnama, S., Febrianta, Y., \& Aziz, H. (2022). Pengembangan Media Busy Book dalam Pembelajaran Motorik Halus Anak Usia 4-5 Tahun. 6(2), 719-727. https:// doi.org/10.31004/obsesi.v6i2.789

Kaimal, G., Ayaz, H., Herres, J., Dieterich-Hartwell, R., Makwana, B., Kaiser, D. H., \& Nasser, J. A. (2017). Functional near-infrared spectroscopy assessment of reward perception based on visual self-expression: Coloring, doodling, and free drawing. Arts in Psychotherapy, 55, 85-92. https://doi.org/10.1016/j.aip.2017.05.004

Lillard, A. S., Hopkins, E. J., Dore, R. A., Palmquist, C. M., Lerner, M. D., \& Smith, E. D. (2013). Concepts and theories, methods and reasons: Why do the children (pretend) play? Reply to Weisberg, Hirsh-Pasek, and Golinkoff (2013); Bergen (2013); and Walker and Gopnik (2013). https:// doi.org/10.1037/a0030521

Mardliyah, S., Yulianingsih, W., \& Putri, L. S. R. (2020). Sekolah Keluarga: Menciptakan Lingkungan Sosial untuk Membangun Empati dan Kreativitas Anak Usia Dini. Jurnal Obsesi : Jurnal Pendidikan Anak Usia Dini, 5(1), 576. https:// doi.org/10.31004/obsesi.v5i1.665

Marwiyati, S., \& Istiningsih, I. (2021). Pembelajaran Saintifik pada Anak Usia Dini dalam Pengembangan Kreativitas di Taman Kanak-Kanak. Jurnal Obsesi : Jurnal Pendidikan Anak Usia Dini, 5(1), 135. https:// doi.org/10.31004/obsesi.v5i1.508

Nasution, N., Yaswinda, Y., \& Maulana, I. (2019). Analisis Pembelajaran Berhitung melalui Media Prisma Pintar pada Anak Usia Dini. Jurnal Obsesi : Jurnal Pendidikan Anak Usia Dini, 4(1), 240. https://doi.org/10.31004/obsesi.v4i1.311

Park, Y. H., \& Choi, Y. Y. (2021). Feeding Practices and Early Childhood Caries in Korean Preschool Children. International Dental Journal, 0, 14-17. https:// doi.org/10.1016/j.identj.2021.07.001

Pizzingrilli, P., Valenti, C., Cerioli, L., \& Antonietti, A. (2015). Creative Thinking Skills from 6 to 17 Years as Assessed Through the WCR Test. Procedia - Social and Behavioral Sciences, 191, 584-590. https:// doi.org/10.1016/j.sbspro.2015.04.498 
Platokhina, N. A., Samarina, I. V., \& Abashina, N. N. (2016). Preventive Measures against Speech Disorders in Early Childhood. Procedia - Social and Behavioral Sciences, 233(May), 247-251. https://doi.org/10.1016/j.sbspro.2016.10.212

Podobnik, U., Peternel, V., \& Selan, J. (2021). Drawing development of identical and nonidentical twins: A case study of triplets. Heliyon, 7(3), e06431. https://doi.org/10.1016/j.heliyon.2021.e06431

Saliceti, F. (2015). Educate for Creativity: New Educational Strategies. Procedia - Social and Behavioral

Sciences, 197(February), 1174-1178. https://doi.org/10.1016/j.sbspro.2015.07.374

Sari, H. M., \& Nofriyanti, Y. (2019). Peningkatan Kreativitas Anak Usia Dini melalui Kegiatan Menganyam dengan Origami. Jurnal Obsesi : Jurnal Pendidikan Anak Usia Dini, 4(1), 146. https:// doi.org/10.31004/obsesi.v4i1.247

Shalihat, I. S., LN, S. Y., \& AS, U. S. (2021). Creative Character Training (CCT): Dampaknya terhadap Karakter Kreatif Guru Pendidikan Anak Usia Dini. Jurnal Obsesi : Jurnal Pendidikan Anak Usia Dini, 6(2), 565-578. https:// doi.org/10.31004/obsesi.v6i2.1352

Suryana, D. (2016). Pendidikan Anak Usia Dini: Stimulasi \& Aspek Perkembangan Anak. Prenada Media.

Wahyuningsih, S., Pudyaningtyas, A. R., Hafidah, R., Syamsuddin, M. M., Nurjanah, N. E., \& Rasmani, U. E. E. (2019). Efek Metode STEAM pada Kreatifitas Anak Usia 5-6 Tahun. Jurnal Obsesi: Jurnal Pendidikan Anak Usia Dini, 4(1), 305. https://doi.org/10.31004/obsesi.v4i1.305 